\title{
Zastosowanie obrazów funkcjonalnych w planowaniu leczenia radioterapii ze szczególnym uwzględnieniem metody „dose painting”
}

\section{Use of functional areas in radiotherapy treatment planning with particular reference to the dose painting method}

\author{
Małgorzata Skórska ${ }^{1}$, Tomasz Piotrowski ${ }^{1,2}$ \\ ${ }^{1}$ Zakład Fizyki Medycznej, Wielkopolskie Centrum Onkologii, Poznań, Polska \\ ${ }^{2}$ Katedra i Zakład Elektroradiologii, Uniwersytet Medyczny, Poznań, Polska
}

\section{Streszczenie}

W ostatnich latach miał miejsce ogromny postęp technologiczny w dziedzinie diagnostyki obrazowej, co niewątpliwie przekłada się na większą skuteczność oraz poprawę jakości leczenia onkologicznego. Obecnie poza typowym trójwymiarowym obrazowaniem anatomii możliwe jest również biologiczne obrazowanie czynnościowe, które można wykorzystać w radioterapii. Polega to na zdeponowaniu odpowiedniej dawki promieniowania jonizującego $\mathrm{w}$ ciele chorego na podstawie indywidualnych procesów biologicznych zachodzących w obszarze zmienionym chorobowo. Metoda ta zwana jest „dose painting” (DP). Celem tej pracy jest podsumowanie dotychczasowych doniesień literaturowych poruszających zagadnienie DP. Opisane zostaną również ograniczenia tej metody.

\begin{abstract}
In recent years, there has been a major technological progress in the field of diagnostic imaging, which undoubtedly translates into greater efficiency and higher quality of cancer treatment. Currently, besides a typical three-dimensional imaging of the anatomy, it is also possible to perform a biological functional imaging that can be later used in radiotherapy. The idea is to deposit an appropriate dose of ionizing radiation to the patient's body based on individual biological processes that take place in the area affected by the tumor. This method is called „dose painting” (DP). The aim of this paper is to summarize the literature related to DP. The limitations concerned with this method will also be described.
\end{abstract}

Stowa kluczowe: rose painting, PET, radioterapia, obrazy funkcjonalne, fMRI

Keywords: dose painting, PET, radiotherapy, functional imaging, fMRI

Adres do korespondencji

mgr Małgorzata Skórska,

Zakład Fizyki Medycznej,

Wielkopolskie Centrum Onkologii, ul. Garbary 15, 61-866 Poznań, Polska

Telefon: +48618850553; Fax +48618850551

e-mail: malgorzata.skorska@wco.pl 


\section{Wstęp}

Techniki obrazowe odgrywają bardzo ważną rolę w procesie planowania leczenia radioterapii (RT). Obecnie najpopularniejszą techniką jest tomografia komputerowa CT (ang. Computed Tomograpy), którą stosuje się m. in. w celu określenia obszaru guza nowotworowego - GTV (ang. Gross Tumor Volume) oraz narządów krytycznych (OAR, ang. Organ at Risk). Ponadto na podstawie obrazów CT możliwe jest oszacowanie rozkładu dawki w ciele pacjenta, a dzięki nowoczesnym technikom np. IMRT (ang. Intensity Modulated Radiation Therapy) istnieje możliwość uzyskania jednorodnej i konformalnej dawki w obszarze tarczowym przy jednoczesnej ochronie sąsiednich narządów [1-2].

W 2000 roku po raz pierwszy Ling et al. [3] zasugerował, aby w planowaniu radioterapii oprócz standardowych obrazów radiologicznych, dających jedynie informacje anatomiczne, zastosować również obrazy funkcjonalne, które dostarczą dodatkowych informacji na temat metabolizmu, funkcjonalności morfologicznej, fizjologii, genotypu czy fenotypu. Ponadto, podczas procesu przygotowywania trójwymiarowej rekonstrukcji rozkładu dawki w ciele pacjenta fizyczna konformalność zostałaby zastąpiona przez biologiczną konformalność. Oznacza to, że plan leczenia każdego pacjenta byłyby zindywidualizowany nie tylko do jego warunków anatomicznych, ale również do procesów biologicznych zachodzących w jego ciele. Mając informację o zróżnicowaniu tkanek wewnątrz guza nowotworowego na podstawie obrazów funkcjonalnych, można by zwiększyć kontrolę miejscową poprzez dostarczenie odpowiednio większej dawki promieniowania jonizującego w miejsca szczególnie oporne na radioterapię. Taki rodzaj eskalacji dawki w literaturze nosi nazwę „dose painting” (DP). Metoda ta jest obecnie intensywnie badana przez wiele ośrodków naukowych [4-7], gdyż wiążą się z nią liczne aspekty, które należy rozstrzygnąć zanim DP zostanie zastosowane rutynowo w praktyce klinicznej. Pojawiły się również pierwsze doniesienia na temat badań klinicznych z zastosowaniem DP. [4-5]

\section{Cel}

Celem publikacji jest podsumowanie dotychczasowych doniesień dotyczących DP. W pracy omówione zostaną strategie planowania rozkładu dawki z uwzględnieniem DP oraz możliwości wykorzystania różnych obrazów funkcjonalnych w planowaniu leczenia radioterapii. Ponadto poruszone zostaną aspekty związane z potencjalnymi ograniczeniami oraz niepewnościami metody DP w praktyce klinicznej.

\section{Material i metoda}

W celu usystematyzowania informacji dotyczących eskalacji dawki metodą DP, przeprowadzono analizę literatury przy użyciu wyszukiwarki PubMed. Analizę przeprowadzono dla słów kluczowych w języku angielskim. Użyte słowa kluczowe ułożono według następującego schematu: dose painting or functional imaging and radiotherapy.

W wyniku wyszukiwania do wstępnej analizy zakwalifikowano 181 publikacji pochodzących z lat 200o2015. Wyłonione w wyniku wyszukiwania publikacje poddano wstępnej analizie z wykorzystaniem tekstu zawartego w ich streszczeniach. Ostatecznie, do szczegółowej analizy wyłoniono 17 prac, które stanowią podstawę niniejszego opracowania.

\section{Wyniki i omówienie}

\section{- Strategie planowania leczenia w oparciu o DP}

Diagnostyka molekularna może być wykorzystana w onkologii na szereg sposobów:

(a) diagnoza oraz klasyfikacja etapu choroby nowotworowej - obrazowanie jest wykonywane na początku leczenia w celu potwierdzenia obecności guza nowotworowego oraz zweryfikowania stopnia zaawansowania choroby;

(b) zdefiniowanie obszaru tarczowego - obrazowanie jest wykonywane przed rozpoczęciem radioterapii w celu zdefiniowania nowotworu oraz sąsiadujących tkanek zdrowych; 
(c) ocena leczenia - obrazowanie jest wykonywane w trakcie lub po zakończeniu radioterapii, aby ustalić skuteczność leczenia lub zmodyfikować terapię, w celu zwiększenia jej skuteczności.

Obrazy funkcjonalne, które najczęściej są wykorzystywane w celu planowania leczenia z uwzględnieniem DP (wyżej wymieniona kategoria b) to pozytronowa tomografia emisyjna (PET). Najpopularniejszymi znacznikami wykorzystywanymi w tym celu są ${ }^{18} \mathrm{~F}$-fludeoksyglukoza (FDG), Cu-ATSM, ${ }^{18} \mathrm{~F}$-fluoromizonidazol (FMISO), ${ }^{18} \mathrm{~F}$ - fluorotymidyna (FLT) oraz ${ }^{18} \mathrm{~F}$-arabinozyd-fluoroazomycyny (FAZA).

FDG obrazuje metabolizm komórkowy i jest obecnie najbardziej rozpowszechnionym oraz najlepiej poznanym znacznikiem. Wiele tkanek nowotworowych wykazuje zwiększone gromadzenie FDG, co jest związane z większym tempem glikolizy oraz transportu glukozy. Obecnie badanie PET z użyciem FDG wykorzystuje się do oceny stopnia zaawansowania przed leczeniem oraz określenia objętości tarczowej. Ponadto wykazano, że wykonanie badania FDG PET w początkowym okresie leczenia umożliwia przewidywanie odpowiedzi terapeutycznej, natomiast wykonanie tego badania po leczeniu pozwala określić resztkową masę nowotworu [12,13]. Niestety są obszary (np. mózgowie czy prostata), gdzie obrazowanie za pomocą FDG jest nieadekwatne z powodu niskiego stosunku sygnału do szumu. W związku z tym poszukuje się nowych alternatywnych znaczników.

Poza znacznikami obrazującymi metabolizm komórkowy wiele uwagi poświęca się na obrazowanie obszaru hipoksji, gdyż ma ona istotny wpływ na progresję wielu nowotworów. Hipoksyczne mikrośrodowisko guza sprawia, iż komórki nowotworowe są bardziej agresywne i odporne na leczenie [14]. Badania z użyciem Cu-ATSM, FMISO oraz FAZA wykazały obiecujące wyniki w badaniach prospektywnych m.in. u pacjentów z niedrobnokomórkowym rakiem płuca czy rakiem szyjki macicy.

FLT jest znacznikiem obrazującym proliferację komórek w guzie. Dla wielu typów nowotworów wykazano, że proliferacja komórek nowotworowych jest częstą przyczyną niepowodzenia radioterapii.

Niewiele jest badań dotyczących wykorzystania rezonansu magnetycznego (MR) do eskalacji dawki w oparciu o metodę DP. Najczęściej analizowane są dane pochodzące z badań dynamicznych z kontrastem (DCE-MRI) lub spektroskopii MR. Metodę DCE-MRI można zastosować w celu zweryfikowania np. utlenowania guza nowotworowego [15]. Zahra et al. [16] wykazał iż metoda ta może mieć istotne znaczenie w zwiększenia indeksu terapeutycznego, poprzez zindywidualizowanie procesu radioterapii. Natomiast metoda spektroskopii MR pozwala zidentyfikować regiony o nieprawidłowej aktywności metabolicznej. Na przykład, w raku prostaty bada się stosunek choliny i kreatyny do cytrynianu [17], który dobrze koreluje ze wskaźnikiem Gleasona [18], a co za tym idzie z agresywnością nowotworu. W rezultacie można by zwiększyć dawkę promieniowania jonizującego w miejscach o nieprawidłowej aktywności metabolicznej, co zwiększyło by indeks terapeutyczny [19].

Należy pamiętać, że w każdym z omawianych przypadków obrazy funkcjonalne zapisywane są w medycznym formacie obrazów cyfrowych (DICOM). Obraz DICOM, jak każdy obraz cyfrowy składa się ze zbioru pikseli. Piksel jest najmniejszym jednolitym elementem obrazu wyświetlanego na ekranie, drukowanego lub uzyskiwanego za pomocą urządzeń przetwarzania obrazu. O ile piksel jest jednostką elementarną dla pojedynczego obrazu przedstawionego w geometrii dwuwymiarowej, to w przypadku trójwymiarowej rekonstrukcji obrazów DICOM jednostkę elementarną stanowi woksel (ang. voxel). Dlatego też w przypadku badań funkcjonalnych wykonanych przy użyciu metody PET dokładność oceny odkładania się radiofarmaceutyku w poszczególnych elementach objętości ciała pacjenta ograniczona jest wielkością woksela.

\section{- Metody DP}

Eskalacja dawki metodą DP może odbywać się na dwa sposoby: DPBC (ang. Dose Painting By Contours) lub DPBN (ang. Dose Painting By Numbers). Pierwsza koncepcja polega na zdefiniowaniu dodatkowego obszaru tarczowego tzw. funkcjonalnego GTV (fGTV) na podstawie obrazów molekularnych i następnie, na jednorodnym zwiększeniu w tym rejonie dawki terapeutycznej [3]. Natomiast DPBN polega na wykorzystaniu niejednorodności sygnału w obrazach funkcjonalnych i następnie przypisanie wokselom niejednorodnej dawki promieniowania jonizującego np. dla obrazów PET, wyższy sygnał związany z większą kumulacją radiofarmaceutyku w obszarze fGTV, odpowiada wyższej dawce terapeutycznej [8].

Idea DPBC została po raz pierwszy przedstawiona przez Ling et al. [3]. Zaproponował on, aby zobrazować 

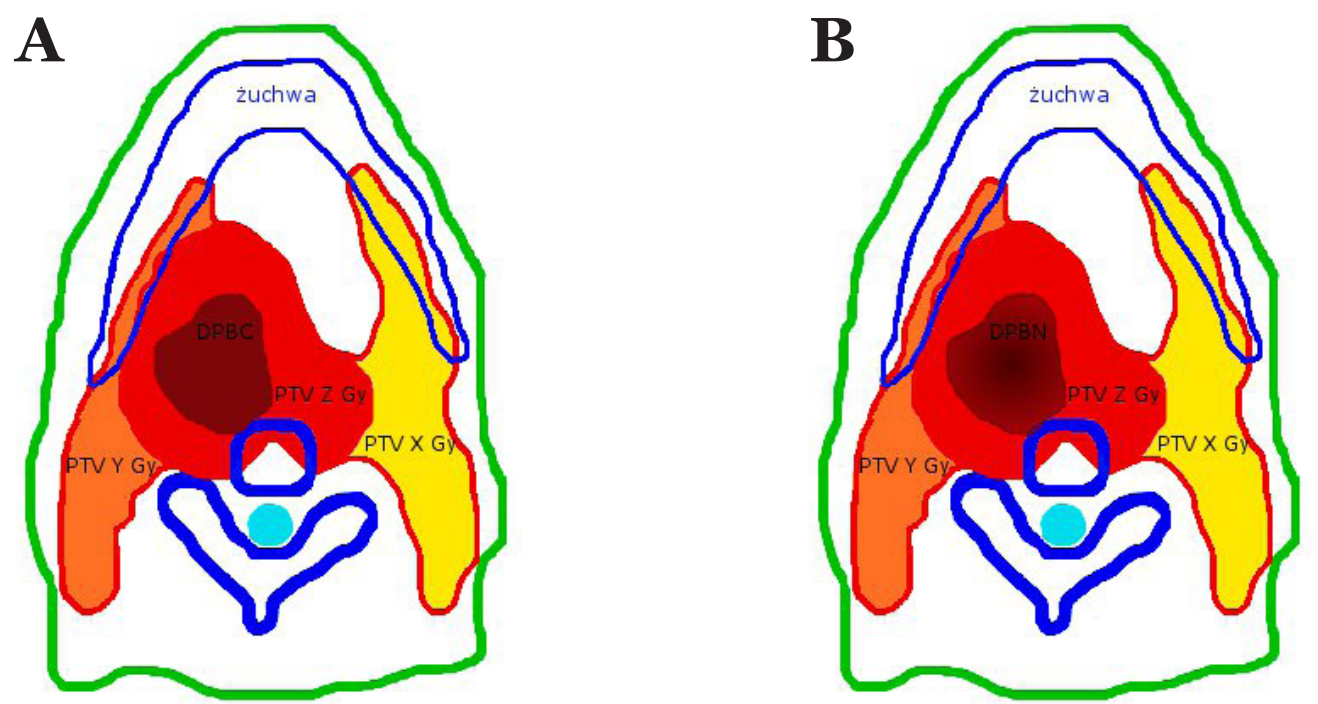

Rycina 1. Schematyczne przedstawienie dwóch strategii planowania leczenia w oparciu o metodę „dose painting" (DP): A - metoda dose painting by contours (DPBC); B - metoda dose painting by numbers (DPBN). PTV - Planning Target Volume: X Gy < Y Gy < Z Gy.

obszary nowotworu, które są szczególnie oporne na radioterapię i następnie lokalnie zwiększyć w tym rejonie dawkę promieniowania jonizującego. Rok później Chao et al. [9], zastosował tę koncepcję w swojej pracy. Na podstawie obrazów PET ze znacznikiem 64Cu-diacetylo-bis(N4metiosemikarabazon) (Cu-ATSM) zdefiniowany został obszar hipoksji u pacjenta z nowotworem zlokalizowanym w obszarze głowy i szyi. Następnie zaplanowano hipotetyczny rozkład dawki, w którym dawka terapeutyczna została podwyższona do 80 Gy (35 frakcji) w obszarze hipoksji, podczas gdy reszta obszaru tarczowego otrzymała dawkę 70 Gy (35 frakcji). Plan został wykonany w technice tzw. boostu symultanicznego (SIB, ang. Simultaneously Integrated Boost), która wydaje się najbardziej odpowiednią techniką dla metody DP. Na rycinie 1A przedstawiono schematycznie rozkład dawki dla przypadku DPBC. Warto zauważyć, że dawka w obszarze wyznaczonym podług badania PET w metodzie DPBC powinna być jednorodna.

Nowszą i zarazem bardziej wyrafinowaną strategią planowania leczenia w oparciu o DP jest metoda DPBN, którą zaproponował Bentzen [8] w 2005 roku. Polega ona na przypisaniu każdemu wokselowi w obrębie zwiększonego wychwytu znacznika (fGTV) odpowiednią dawkę promieniowania jonizującego. Obecnie nie jest znana zależność między intensywnością sygnału powstałego w wyniku kumulacji radiofaramcutyku w objętości ciała pacjenta reprezentowanej przez woksel a wielkością dawki, która powinna być zdeponowana w tymże wokselu. W związku z tym w większości prac przyjęto założenie, iż jest to zależność liniowa [4-7,1011]. Na rycinie $1 \mathrm{~B}$ przedstawiono schematycznie rozkład dawki dla przypadku DPBN. W odróżnieniu od metody DPBC (ryc. 1A), w metodzie DPBN (ryc. 1B) zakłada się, że dawka w obszarze fGTV jest niejednorodna i jej niejednorodność uwarunkowana jest w sposób np. liniowy intensywnością sygnału wychwytu radiofarmaceutyku przez poszczególne woksele zawarte w fGTV.

\section{- Ocena jakości planu przygotowanego z uwzględnieniem metody DP}

W przypadku DPBC ocena jakości planu leczenia przeprowadzana jest według klasycznych metod polegających na analizie zaplanowanych rozkładów dawek. Uwzględnia ona weryfikację:

- histogramów wizualizujących zależności pomiędzy dawką i objętościami struktur, które poddane zostaną napromienianiu,

- parametrów statystycznych charakteryzujących rozkład dawki (średnia, mediana, minimum, maksimum, odchylenie standardowe),

- $\quad$ współczynników konformalności i homogenności rozkładu dawki.

Typowe metody oceny jakości planu nie są jednak wystarczające podczas ewaluacji planów leczenia wykonanych metodą DPBN z powodu konieczności uzyskania niejednorodnego rozkładu dawki w obszarze 


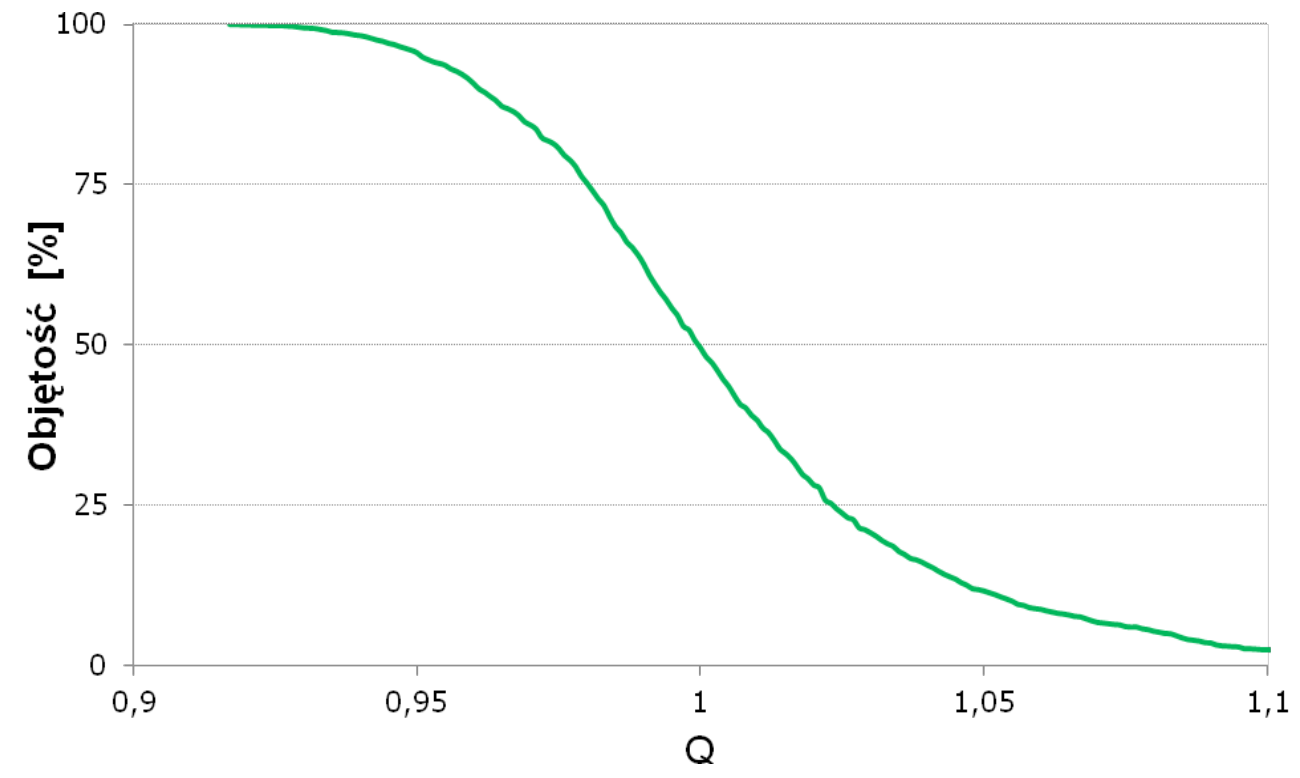

Rycina 2. Przykładowy wykres histogramu jakość - objętość (QVH) dla pacjenta z nowotworem zlokalizowanym w obrębie głowy i szyi, gdzie rozkład dawki został zaplanowany metodą dose painting by numbers (DPBN).

fGTV. Vanderstraeten et al. [6] zaproponowała użycie współczynnika jakości (ang. quality factor - QF) oraz histogramu jakość-objętość (ang. Q-Volume Histogram - QVH). Gdy cały obszar fGTV zostanie podzielony na zbiór punktów $(\mathrm{p}=1,2,3, \ldots, \mathrm{n})$, wówczas dla dowolnego punktu p można obliczyć jakość dawki $\left(\mathrm{Q}_{\mathrm{p}}\right)$ jako stosunek dawki zamierzonej $\left(\mathrm{D}_{\mathrm{p}}\right)$ do dawki zaplanowanej w systemie planowania leczenia $\left(\mathrm{D}_{\text {zapl }}\right)_{\mathrm{p}}$ :

$$
\mathrm{Q}_{\mathrm{p}}=\mathrm{D}_{\mathrm{p}} /\left(\mathrm{D}_{\text {zapl }}\right)_{\mathrm{p}}
$$

Gdy obliczymy średnie całkowite odchylenie wartości Q od 1 dla wszystkich punktów p wówczas otrzymamy współczynnik jakości QF:

$$
Q F=\frac{1}{n} \sum_{p=1}^{p=n}\left|Q_{p}-1\right|
$$

który jest miarą jakości rozkładu dawki DPBN w obszarze fGTV.

Gdy wykreślona zostanie objętość fGTV w funkcji wartości Q, wówczas otrzymamy QVH. Przykładowy wykres QVH dla pacjenta z nowotworem zlokalizowanym w obrębie głowy i szyi, gdzie rozkład dawki został zaplanowany metodą DPBN przedstawiono na rycinie 2.

W idealnej sytuacji, gdyby w każdym punkcie p dawka zamierzona w stosunku do dawki zaplanowanej była taka sama QVH byłby linią prostą w punkcie $\mathrm{Q}=1$, natomiast $\mathrm{QF}$ wyniósł by o.

Park etal. [20] zaproponował inny współczynniktzw. wskaźnik realizacji (index of achievement-IOA), który jest średnią ważoną po objętości z różnicy między dawką zamierzoną a zaplanowaną. Ponadto wprowadził dodatkowe dwa współczynniki: wskaźnik gorąca (index of hotness - IOH) oraz zimna (index of coldness IOC), w celu oceny miejsc gdzie dawka zaplanowana jest znacznie wyższa lub niższa od zamierzonej.

\section{- Ograniczenia i niepewności metod DP}

Jednym z głównych ograniczeń w eskalacji dawki metodami DP jest wielkość woksela w obrazach PET, która wynosi 3-5mm. W porównaniu do np. hipoksji, którą obserwuje się w skali rzędu kilkuset mikrometrów jest to ogromna różnica. W związku z tym nieunikniony jest błąd związany z precyzyjnym wyznaczeniem obszaru fGTV wynikający z uśrednienia różnych zjawisk biologicznych zachodzących w jednym wokselu PET [21]. Należy również wspomnieć o algorytmach rekonstrukcyjnych, które przyczyniają się do wprowadzenia dodatkowych szumów na obrazie. W związku z tym dokładne zróżnicowanie guza na obrazach funkcjonalnych 
jest bardzo trudne. O ile w przypadku metody DPBC ograniczenia te wpływają jedynie na dokładność wyznaczenia ogólnego kształtu fGTV będącego zbiorem wokseli, to w przypadku DPBN multiplikują się przez konieczność precyzyjnej detekcji każdego woksela obszaru fGTV z osobna.

Ponadto nadal jest wiele pytań i wątpliwości dotyczących zależności intensywności sygnału niesionego przez woksele w obrazach funkcjonalnych, a dawką promieniowania jonizującego. Obecnie w badaniach przyjęto, iż jest ona liniowa. Aczkolwiek założenie to jest czysto hipotetyczne. Stąd planowanie leczenia metodą DP bywa poddane w wątpliwość.

Kolejnym problemem jest fakt, iż plany leczenia z eskalacją dawki metodą DP są bardzo czułe na geometryczne błędy podczas radioterapii wiązkami zewnętrznymi. Korreman et al. [10] wykazała, że błąd systematyczny wielkości $2 \mathrm{~mm}$ w każdym kierunku skutkuje znacznym spadkiem konformalności rozkładu dawki. Porównując zaplanowany rozkład dawki z rozkładem, w którym wprowadzono wyżej wymieniony błąd - jedynie 53-60\% objętości PTV mieściło się w zakresie $\pm 5 \%$ wartości dawki zaplanowanej. W ostatnim czasie ukazały się jednak publikacje, które prezentują rozwiązanie tego problemu [22, 23].

Mimo powyższych ograniczeń, badania kliniczne I fazy dotyczące eskalacji dawki metodą DP w oparciu o obrazy funkcjonale prowadzone są w ośrodku w Ghent w Belgii. Badanie dotyczy pacjentów z rakiem w rejonie głowy i szyi i oparte jest na obrazach FDG-PET [4-5].

\section{Wnioski}

Planowanie leczenia metodą DP w oparciu o obrazy funkcjonalne jest przykładem zindywidualizowanego podejścia do leczenia, które wydaje się bardzo obiecujące. Jednak kliniczne zastosowanie tej metody jest bardzo wymagające zarówno przed, jak i w trakcie radioterapii. Niezbędne są badania kliniczne, które wykażą wymierny zysk ze stosowania metody DP oraz określą poziom dawki promieniowania jonizującego, który powinien być zdeponowany w obszarze fGTV.

\section{Etyka/Ethics}

Treści przedstawione w artykule są zgodne z zasadami Deklaracji Helsińskiej, dyrektywami EU oraz ujednoliconymi wymaganiami dla czasopism biomedycznych.

\section{Finansowanie/Financial support}

Praca była finansowana $\mathrm{z}$ grantu Wielkopolskiego Centrum Onkologii w Poznaniu, nr 8/2015(100);16/03/2015/FIZ/WCO/4 ./This work was supported by the Greater Poland Cancer Centre, grant no. 8/2015(100);16/03/2015/FIZ/WCO/4 .

\section{Konflikt interesu/Conflict of interest}

Nie występuje.

\section{Piśmiennictwo}

Litoborska J. Najnowsze technologie wykorzystywane w procesie teleradioterapii w świetle doniesień konferencyjnych ASTRO 56. Zeszyty Naukowe WCO, Letters in Oncology Science 2015;12:33-36

[1] Bandurska-Luque A, Piotrowski T, Skrobała A, Ryczkowski A, Adamska K, Kaźmierska J. Prospective study on dosimetric comparison of helical tomotherapy and 3DCRT for craniospinal irradiation A single institution experience. Rep Pract Oncol Radiother 2015;20:145-152.

[2] Ling CC, Humm J, Larson S, Amols H, Fuks Z, Leibel S, et al. Towards multidimensional radiotherapy (MD-CRT): biological imaging and biological conformality. Int J Radiat Oncol Biol Phys. 2000;47(3):55160

[3] Duprez F, De Neve W, De Gersem W, Coghe M, Madani I. Adaptive dose painting by numbers for head- 
and-neck cancer. Int J Radiat Oncol Biol Phys. 2011; 80(4):1045-55. doi:10.1016/j.ijrobp.2010.03.028

[4] Madani I, Duthoy W, Derie C, De Gersem W, Boterberg T, Saerens M, et al. Positron emission tomographyguided, focal-dose escalation using intensity-modulated radiotherapy for head and neck cancer. Int $\mathrm{J}$ Radiat Oncol Biol Phys. 2007;68(1):126-35. doi:10.1016/j.ijrobp.2006.12.070

[5] Vanderstraeten B, Duthoy W, De Gersem W, De Neve W, Thierens H. [18F]fluoro-deoxy-glucose positron emission tomography ([18F]FDG-PET) voxel intensity-based intensity-modulated radiation therapy (IMRT) for head and neck cancer. Radiother Oncol 2006;79(3):249-58. doi:10.1016/j.radonc.2006.03.003

[6] Deveau MA, Bowen SR, Westerly DC, Jeraj R. Feasibility and sensitivity study of helical tomotherapy for dose painting plans. Acta Oncol 2010;49(7):991-6. doi: 10.3109/0284186X.2010.500302

[7] Bentzen SM. Theragnostic imaging for radiation oncology: dose-painting by numbers. Lancet Oncol 2005; 6:112-7.

[8] Chao KS, Bosch WR, Mutic S, et al. A novel approach to overcome hypoxic tumor resistance. Cu-ATSM guided intensity modulated radiation therapy. Int J Radiat Oncol Biol Phys 2001;49:1171-82.

[9] Korreman SS, Ulrich S, Bowen S, Deveau M, Bentzen SM, Jeraj R. Feasibility of dose painting using volumetric modulated arc optimization and delivery. Acta Oncol 2010; 49(7):964-71

[10] Skorska M, Piotrowski T, Ryczkowski A, Kazmierska J. Comparison of treatment planning parameters for dose painting head and neck plans delivered with Tomotherapy. 2016 [in press]

[11] Avril NE, Weber WA. Monitoring response to treatment in patients utilizing PET. Radiol Clin North Am 2005; 43:189-204

[12] Smith TA. FDG uptake, tumor characteristics and response to therapy: a review. Nucl Med Commun 1998; 19:97-105

[13] Padhani AR, Krohn KA, Lewis JS, Alber M. Imaging oxygenation of human tumours. European Radiology. 2007;17(4):861-872.

[14] Søvik A, Malinen E, Olsen DR. Strategies for biologic image-guided dose escalation: a review. Int J Radiat Oncol Biol Phys. 2009;73(3):650-8.

[15] Zahra MA, Hollingsworth KG, Sala E, Lomas DJ, Tan LT. Dynamic contrast-enhanced MRI as a predictor of tumour response to radiotherapy. Lancet Oncol 2007;8:63-74.

[16] Costello LC, Franklin RB, Narayan P. Citrate in the diagnosis of prostate cancer. Prostate 1999;38:237245.

[17] Zakian KL, Sircar K, Hricak H, et al. Correlation of proton MR spectroscopic imaging with Gleason score based on step-section pathologic analysis after radical prostatectomy. Radiology 2005;234:804-814.

[18] Speight JL, Roach M 3rd. Advances in the treatment of localized prostate cancer: The role of anatomic and functional imaging In men managed with radiotherapy. J Clin Oncol 2007;25: 987-95.

[19] Park YK, Park S, Wu HG, Kim S. A new plan quality index for dose painting radiotherapy. J Appl Clin Med Phys 2014;15(4):4941. doi: 10.1120/jacmp.v15i4.4941

[20] Thorwarth D, Alber M. Implementation of hypoxia imaging into treatment planning and delivery. Radiother Oncol 2010;97(2):172-5. doi: 10.1016/j.radonc.2010.05.012.

[21] Sterpin E, Differding S, Janssens G, Geets X, Grégoire V, Lee JA. Generation of prescriptions robust against geometric uncertainties in dose painting by numbers. Acta Oncol 2015;54(2):253-60. doi: 10.3109/0284186X.2014.930171.

[22] Witte M, Shakirin G, Houweling A, Peulen H, van Herk M. Dealing with geometric uncertainties in dose painting by numbers: introducing the $\Delta V H$. Radiother Oncol 2011;100(3):402-6. doi: 10.1016/j. radonc.2011.08.028. 